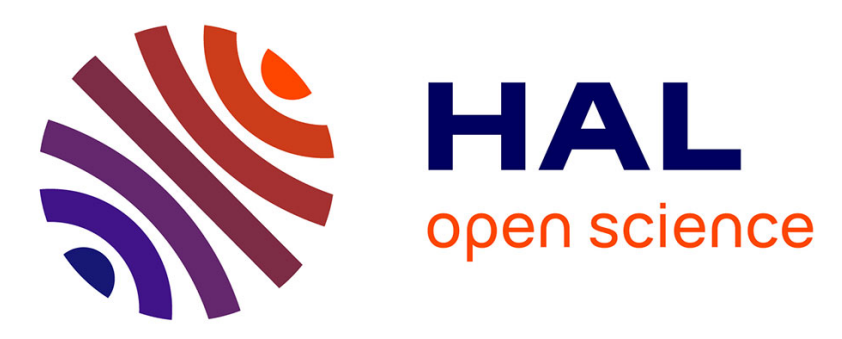

\title{
Differential interactions of carbamate pesticides with drug transporters
}

Nelly Gueniche, Arnaud Bruyère, Mélanie Ringeval, Elodie Jouan, Antoine Huguet, Ludovic Le Hegarat, Olivier Fardel

\section{- To cite this version:}

Nelly Gueniche, Arnaud Bruyère, Mélanie Ringeval, Elodie Jouan, Antoine Huguet, et al.. Differential interactions of carbamate pesticides with drug transporters. Xenobiotica, 2020, 50 (11), pp.1380-1392. 10.1080/00498254.2020.1771473 . anses-02626126

\section{HAL Id: anses-02626126}

\section{https://hal-anses.archives-ouvertes.fr/anses-02626126}

Submitted on 27 May 2020

HAL is a multi-disciplinary open access archive for the deposit and dissemination of scientific research documents, whether they are published or not. The documents may come from teaching and research institutions in France or abroad, or from public or private research centers.
L'archive ouverte pluridisciplinaire HAL, est destinée au dépôt et à la diffusion de documents scientifiques de niveau recherche, publiés ou non, émanant des établissements d'enseignement et de recherche français ou étrangers, des laboratoires publics ou privés. 
Differential interactions of carbamate pesticides with drug transporters

Nelly Gueniche ${ }^{\mathrm{a}, \mathrm{b}}$, Arnaud Bruyere ${ }^{\mathrm{a}}$, Mélanie Ringeval ${ }^{\mathrm{a}}$, Elodie Jouan ${ }^{\mathrm{a}}$, Antoine Huguet ${ }^{\mathrm{b}}$, Ludovic Le Hégarat ${ }^{\mathrm{b}}$, Olivier Fardel $^{\mathrm{c}, *}$

${ }^{a}$ Univ Rennes, Inserm, EHESP, Irset (Institut de recherche en santé, environnement et travail) - UMR_S 1085, F-35000 Rennes, France

${ }^{\mathrm{b}}$ ANSES (French Agency for Food, Environmental and Occupational Health and Safety), Fougères Laboratory, Toxicology of contaminant unit, F-35306 Fougères, France

c Univ Rennes, CHU Rennes, Inserm, EHESP, Irset (Institut de recherche en santé, environnement et travail) - UMR_S 1085, F-35000 Rennes, France

Corresponding author: Olivier Fardel, Irset, Faculty of Pharmacy, 2 Avenue Pr Léon Bernard, 35043 Rennes, France. E-mail : olivier.fardel@univ-rennes1.fr 


\section{ABSTRACT}

1. Pesticides are now recognised to interact with drug transporters, but only few data are available on this issue for carbamate pesticides, a widely-used class of agrochemicals, to which humans are highly exposed. The present study was therefore designed to determine whether four representative carbamate pesticides, i.e., the insecticides aminocarb and carbofuran, the herbicide chlorpropham and the fungicide propamocarb, may impair activities of main drug transporters implicated in pharmacokinetics.

2. The interactions of carbamates with solute carrier and ATP-binding cassette transporters were investigated using cultured transporter-overexpressing cells, reference substrates and spectrofluorimetry-, liquid chomatography/tandem mass spectrometry- or radioactivity-based methods.

3. Aminocarb and carbofuran exerted no or minimal effects on transporter activities, whereas chlorpropham inhibited BCRP and OAT3 activities and propamocarb decreased those of OCT1 and OCT2, but cis-stimulated that of MATE2-K. Such alterations of transporters however required chlorpropham/propamocarb concentrations in the 5-50 $\mathrm{\mu M}$ range, likely not relevant to environmental exposure. Trans-stimulation assays and propamocarb accumulation experiments additionally suggested that propamocarb is not a substrate for OCT1, OCT2 and MATE2-K.

4. These data indicate that some carbamate pesticides can interact in vitro with some drug transporters, but only when used at concentrations higher than those expected to occur in environmentally-exposed humans.

\section{KEY-WORDS}

Carbamate pesticides; drug transporters; chlorpropham; propamocarb; activity; inhibition 


\section{Introduction}

Drug transporters mediate the passage of xenobiotics across membranes, especially the plasma membrane. They belong to the solute carrier (SLC) or the ATP-binding cassette (ABC) transporter subfamilies (Giacomini et al., 2010). SLC transporters are commonly implicated in drug uptake into cells through facilitated diffusion or secondary active transport, whereas $\mathrm{ABC}$ transporters act as efflux pumps through primary active transport. Transporters are now well-recognised as playing a major role in the different steps of pharmacokinetics, including intestinal absorption, distribution across blood-tissue barriers and biliary and renal elimination (Ayrton and Morgan, 2001; Konig et al., 2013). Inhibition of their activity by some drugs, called «perpetrators», can cause drug-drug interactions due to altered pharmacokinetics profile of co-administrated drugs substrates for the inhibited transporters and termed «victims»(Liu, 2019). This may also triggers adverse toxic effects, due to inhibition of endogenous substrate transport (Nigam, 2015).

There is growing evidence that environmental chemicals, like drugs, can inhibit or be substrates of drug transporters (Clerbaux et al., 2019; Fardel et al., 2012). This notably concerns agrochemicals, belonging to different main chemical classes of pesticides (Buss and Callaghan, 2008; Chedik et al., 2018). Thus, some organochlorine, pyrethroid or organophosphorus pesticides, used at concentrations in the 1-100 $\mu \mathrm{M}$ range, in vitro inhibited activities of various ABC and/or SLC transporters (Bain and LeBlanc, 1996; Bucher et al., 2014; Chedik et al., 2019; Chedik et al., 2017a; Gueniche et al., 2020), whereas, by contrast, neonicotinoid pesticides rather poorly blocked drug transporter activities (Le Vee et al., 2019). Inhibition of transporter activities depends on the nature of the pesticide and of the transporter. Some pesticides, like the pyrethroids allethrin and tetramethrin, the organophosphorus fenamiphos and phosmet or the cyanoimidazole fungicide cyazofamid can inhibit various SLC transporters (Chedik et al., 2019; Chedik et al., 2017a; Song et al., 2020), 
thus demonstrating some lack of specificity, as already reported for inhibition of transporters by marketed drugs (Giacomini et al., 2010). A few pesticides, such as ivermectin and paraquat, have moreover been shown to be substrates for transporters (Chen et al., 2007; Griffin et al., 2005).

If the concept that pesticides can interact with drug transporters is now well-established, as illustrated above, only a relatively small fraction of the total number of pesticides presently used in the world (more than 1000) has however been so far studied for potential interactions with drug transporters (Gueniche et al., 2020). Experimental data with respect to this topic remain thus limited. It is notably the case for carbamate pesticides, extensively used for agricultural and non-agricultural purposes, and presumed to exert various deleterious effects towards human health, including endocrine disruption and carcinogenicity (Dhouib et al., 2016; Miranda-Contreras et al., 2013; Patel and Sangeeta, 2019; Piel et al., 2019). Indeed, only few data have been reported with respect to putative interactions of carbamates with transporters; they demonstrated a lack of inhibitory effects of some carbamates towards activity of the human $\mathrm{ABC}$ efflux pump P-glycoprotein (P-gp/ABCB1) (Bain and LeBlanc, 1996) and an inhibition of the rabbit $A B C$ transporter breast cancer resistance protein (BCRP/ABCG2) by propamocarb (Halwachs et al., 2016). The present study was therefore designed to get insights about putative alteration of transporter activities by carbamate pesticides, to which humans may be highly exposed (Bouvier et al., 2006; Bouvier et al., 2005; Mostafalou and Abdollahi, 2017). For this purpose, we have analysed the effects of four representative carbamates, i.e., the two N-methyl carbamates aminocarb and carbofuran, acting as insecticides through reversible inhibition of insect cholinesterase activity, the herbicide chlorpropham and the fungicide propamocarb, towards activities of main drug transporters implicated in pharmacokinetics. Such transporters were ABC pumps (P-gp, BCRP and multidrug-resistance associated proteins (MRPs/ABCCs)), SLC transporters of 
organic anions (organic anion transporting polypeptide (OATP) 1B1/SLCO1B1, OATP1B3/SLCO1B3, OATP2B1/SLCO2B1, organic anion transporter (OAT) 1/SLC22A6 and OAT3/SLC22A8) and SLC transporters of organic cations (organic cation transporter (OCT) 1/SLC22A1, OCT2/SLC22A2, multidrug and toxin extrusion protein (MATE) 1/SLC47A1 and MATE2-K/SLC47A2). The prototypical N-methylcarbamates aminocarb and carbofuran were found to not, or only poorly, inhibit drug transporters, whereas chlorpropham blocked OAT3 and BCRP activities. With respect to propamocarb, it inhibited activities of OCT1 and OCT2 and cis-stimulated that of MATE2-K, without being substrate for these transporters.

\section{Materials and Methods}

\section{Chemicals}

Carbamate pesticides (aminocarb, carbofuran, chlorpropham and propamocarb, whose chemical structures are indicated in Figure 1), rhodamine 123,6- carboxyfluorescein (6- CF), 2',7'- dichlorofluorescein (DCF), tetraethylammonium bromide (TEA), verapamil, probenecid, amitriptyline, fumitremorgin $\mathrm{C}$, rifamycin $\mathrm{SV}$, sulfobromophthalein (BSP) and glutarate were provided by Sigma-Aldrich (Saint-Quentin Fallavier, France). $\left[1-{ }^{14} \mathrm{C}\right]-\mathrm{TEA}$ (specific activity $3.5 \mathrm{mCi} / \mathrm{mmol}$ ) and $\left[6,7-{ }^{3} \mathrm{H}(\mathrm{N})\right]$-estrone-3-sulfate (E3S) (specific activity $51.8 \mathrm{Ci} / \mathrm{mmol}$ ) were purchased from PerkinElmer (Boston, MA, USA). Hoechst 33342 and carboxy- 2',7'- dichlorofluorescein (CDCF) diacetate were obtained from Life Technologies (Villebon- sur- Yvette, France), whereas 8- fluorescein- cAMP (8- FcA) was from BioLog Life Science Institute (Bremen, Germany) and 4- (4- (dimethylamino)styryl)- Nmethylpyridinium iodide (4-DiASP) from Thermo Fisher Scientific (Waltham, MA, USA).

Stocked solutions of chemicals were commonly prepared in dimethyl sulfoxide (DMSO); final concentrations of solvent in transport assay medium did not exceed $0.2 \%$ (vol/vol). According to the PubChem database web-site (U.S. National Library of Medicine, 
Bethesda, MA, USA) (https://pubchem.ncbi.nlm.nih.gov/), all carbamate pesticides tested in the study were predicted to be water-soluble at $100 \mu \mathrm{M}$, which was the carbamate pesticide concentration initially retained for screening their potential inhibitory effects towards transporter activities.

\section{Cell culture}

Mammary MCF7R cells, overexpressing human P-gp (Jouan et al., 2016b), and hepatoma HuH-7 cells, expressing human MRP2/ABCC2 and MRP4/ABCC4 (Jouan et al., 2016a), were cultured in Dulbecco's modified Eagle medium (DMEM) containing 4.5 g/L D-glucose (Life Technologies, Villebon sur Yvette, France), supplemented with $10 \%$ (vol/vol) fetal calf serum, 1\% (vol/vol) MEM non-essential amino acids solution (Life Technologies), 20 IU/mL penicillin and $20 \mu \mathrm{g} / \mathrm{mL}$ streptomycin, as already reported (Chedik et al., 2017a). Human BCRP-transfected HEK-293 cells (HEK-BCRP cells) (Tournier et al., 2010), kindly donated by $\operatorname{Pr}$ X. Decleves (Faculty of Pharmacy, University Paris-Descartes, Paris, France), were cultured in DMEM supplemented with $10 \%$ (vol/vol) fetal calf serum, $100 \mathrm{IU} / \mathrm{mL}$ amoxicillin, $100 \mu \mathrm{g} / \mathrm{mL}$ erythromycin and $200 \mu \mathrm{g} / \mathrm{mL} \mathrm{G} 418$.

Human HEK-293 cells stably overexpressing human SLC transporters, i.e., OCT1 (HEK-OCT1 cells), OCT2 (HEK-OCT2), MATE1 (HEK-MATE1 cells), MATE2-K (HEKMATE2-K cells), OAT1 (HEK-OAT1 cells), OAT3 (HEK-OAT3 cells), OATP1B1 (HEKOATP1B1), OATP1B3 (HEK-OATP1B3) and OATP2B1 (HEK-OATP2B1 cells), as well as parental wild-type HEK-293 cells (HEK-wt cells) have been previously described (Chedik et al., 2017a). They were routinely cultured in DMEM medium supplemented with 10\% (vol/vol) fetal calf serum, 1\% (vol/vol) MEM non-essential amino acids solution, $20 \mathrm{IU} / \mathrm{mL}$ penicillin, $20 \mu \mathrm{g} / \mathrm{mL}$ streptomycin, and $1 \mu \mathrm{g} / \mathrm{mL}$ bovine insulin (Sigma-Aldrich). 
The effects of carbamates on activity of ABC and SLC transporters were determined through measuring cellular accumulation or retention of reference substrates for transporters, in the presence or absence of reference inhibitors, as previously described (Chedik et al., 2017a). The nature of cells and reference substrates and inhibitors as well as incubation times and analytical methods used for transport assays are summarised in Supplementary Table S1.

For accumulation assays, transporter-expressing cells were first incubated at $37^{\circ} \mathrm{C}$ with reference substrates in the absence (control) or presence of carbamate pesticides or reference inhibitors, in a well-defined transport assay medium (Chedik et al., 2017a), consisting of 136 $\mathrm{mM} \mathrm{NaCl}, 5.3 \mathrm{mM} \mathrm{KCl}, 1.1 \mathrm{mM} \mathrm{KH}{ }_{2} \mathrm{PO}_{4}, 0.8 \mathrm{mM} \mathrm{MgSO}$, $1.8 \mathrm{mM} \mathrm{CaCl} 2,10 \mathrm{mM}$ HEPES, $11 \mathrm{mM}$ D-glucose and adjusted to $\mathrm{pH}=7.4$ (excepted for MATE transporter assays, for which $\mathrm{pH}$ was set to 8.4). After washing twice in phosphate-buffered saline (PBS), cells were lysed in distilled water. Intracellular accumulation of reference substrates was finally determined by scintillation counting (for $\left[{ }^{14} \mathrm{C}\right]-\mathrm{TEA}$ and $\left[{ }^{3} \mathrm{H}\right]-\mathrm{E} 3 \mathrm{~S}$ ) using a Tri-Carb ${ }^{\odot}$ 2910TR analyzer (PerkinElmer) or by spectrofluorimetry using a SpectraMax Gemini SX spectrofluorometer (Molecular Devices, Sunnyvale, CA, USA) (for rhodamine 123, 6-CF, DCF, 8- FcA and 4DiASP). Liquid chromatography-tandem mass spectroscopy (LC-MS/MS), based on a highperformance liquid chromatography Aria system (Agilent, Les Ulis, France), equipped with a Poroshell $120 \mathrm{C} 18(4.6 \times 150 \mathrm{~mm})$ column (Agilent, Les Ulis, France) and coupled to a tandem mass spectrometry TSQ Quantum Ultra (Thermo Fisher Scientific, Villebon sur Yvette, France), fitted with an electrospray ionization source (ESI+), was additionally used for analysing unlabeled TEA; monitored ion transitions were at $130.2>86.1 \mathrm{~m} / \mathrm{z}$. Intracellular accumulations of substrates were finally normalised to cellular protein content, determined by the Bradford method (Bradford, 1976). 
For efflux assays, transporter- expressing cells were first incubated at $37^{\circ} \mathrm{C}$ for $30 \mathrm{~min}$ with the reference substrate (CDCF used under its diacetate form or Hoechst 33342) (loading phase), in the transport assay medium described above and as indicated in Supplementary Table S1. After washing in PBS, the cells were re-incubated in substrate- free medium in the absence or presence of carbamate pesticides or reference inhibitors (efflux phase). The cells were then washed twice in ice- cold PBS and cellular levels of substrates were measured by spectrofluorimetry and normalised to cellular protein content.

Data were finally expressed as percentages of substrate accumulation (for accumulation assays) or retention (for efflux assays) found in control cells not exposed to carbamate pesticide or reference inhibitor, arbitrary set at $100 \%$. Alternatively, data were expressed as percentages of transporter activity, according to the following equations:

For SLC transporters:

$$
\text { Transporter activity }(\%)=\frac{\left[\text { Substrate }_{\text {Pesticide }}\right]-\left[\text { Substrate }_{\text {Reference inhibitor }}\right]}{\left[\text { Substrate }_{\text {Controle }}\right]-\left[\text { Substrate }_{\text {Reference inhibitor }}\right]} \times 100
$$

For $\mathrm{ABC}$ transporters :

$$
\text { Transporter activity }(\%)=\frac{\left[\text { Substrate }_{\text {Reference inhibitor }}\right]-\left[\text { Substrate }_{\text {Pesticide }}\right]}{\left[\text { Substrate }_{\text {Reference inhibitor }}\right]-\left[\text { Substrate }_{\text {Control }}\right]} \times 100
$$

with $[$ Substrate Pesticide $]=$ cellular concentration of the reference substrate in the presence of a defined concentration of carbamate pesticide, $\left[\right.$ Substrate Reference $\left._{\text {inhibitor }}\right]=$ cellular concentration of the reference substrate in the presence of the reference inhibitor and $[$ Substrate Control $]=$ cellular concentration of the reference substrate in control cells exposed neither to carbamate pesticide nor to the reference inhibitor.

Some data were also expressed as percentages of reduction of transporter activity using the following equation: 


\section{Transporter activity reduction (\%) $=100-A$}

with $\mathrm{A}=$ percentage of transporter activity in the presence of a given concentration of carbamate pesticide, determined as described in equation (A) or equation (B). According to the US Food and Drug Administration (FDA), a threshold of 50\% transporter activity reduction can be retained for fully validating the effect of a transporter inhibitor (Giacomini et al., 2010).

\section{Trans-stimulation assays}

Trans-stimulation corresponds to the stimulation of the transport of the labeled substrate in response to the presence of a chemical (the stimulating agent) on the opposite side of the transporting membrane (Wright and Wunz, 1988), whereas, for cis-stimulation, the labeled substrate and the stimulating agent are present at the same side of the transporting membrane. Because substrates are considered to trans-stimulate some SLC transporters, trans-stimulation studies permit to identify such substrates (Sweet et al., 2003; Zhang et al., 1999). Transstimulation assays were performed as previously described (Chedik et al., 2017a; Sayyed et al., 2017). Briefly, transporter-expressing HEK-293 cells were first preloaded with unlabeled reference substrates (2 mM TEA for OCT1, OCT2 and MATE2-K and $1 \mathrm{mM}$ glutarate for OAT3) or $100 \mu \mathrm{M}$ carbamate pesticides for $15 \mathrm{~min}$ (HEK-OAT3 cells) or $30 \mathrm{~min}$ (HEKOCT1, HEK-OCT2 and HEK-MATE2-K cells) at $37^{\circ} \mathrm{c}$ in the transport assay medium described above. After washing twice with PBS, cells were next re-incubated in transport assay medium containing $29 \mu \mathrm{M}\left[{ }^{14} \mathrm{C}\right]$-TEA (HEK-OCT1, HEK-OCT2 and HEK-MATE2-K cells) or $10 \mu \mathrm{M}$ 6-CF (HEK-OAT3 cells) for $5 \mathrm{~min}$ at $37^{\circ} \mathrm{C}$. After washing twice with PBS, cells were lysed in distilled water and intracellular accumulations of $\left[{ }^{14} \mathrm{C}\right]-\mathrm{TEA}$ and $6-\mathrm{CF}$ were then determined by scintillation counting or spectrofluorimetry, respectively, and normalised to cellular protein content. 
HEK-OCT1, HEK-OCT2, HEK-MATE2-K and parental HEK-wt cells were incubated with $100 \mu \mathrm{M}$ propamocarb or $29 \mu \mathrm{M}\left[{ }^{14} \mathrm{C}\right]$-TEA for $5 \mathrm{~min}$ at $37^{\circ} \mathrm{C}$, in the transport assay medium defined above. Cells were next washed twice in ice-cold PBS and lysed in distilled water. Cellular accumulation of propamocarb was then determined by LC-MS/MS using the system described above; monitored ion transitions were at $189.1>144.1 \mathrm{~m} / \mathrm{z} . \quad\left[{ }^{14} \mathrm{C}\right]-\mathrm{TEA}$ accumulation was determined by scintillation counting. Data were normalised to protein content. Accumulation of propamocarb and TEA in transporter-overexpressing HEK cells were finally expressed as fold-change comparatively to propamocarb or TEA accumulation found in control parental HEK-wt cells.

\section{Determination of kinetic parameters}

Half maximal inhibitory concentrations $\left(\mathrm{IC}_{50}\right)$ of chlorpropham towards BCRP activity and of propamocarb towards OCT1 and OCT2 activities and half maximal effective concentration $\left(\mathrm{EC}_{50}\right)$ of propamocarb toward MATE2-K activity were determined from nonlinear regression of concentration-response data based on the four parameter logistic function. They were calculated using GraphPad Prism software 8.3 (GraphPad Software, San Diego, CA, USA) through the following equations:

For $\mathrm{IC}_{50}$ :

$$
A=\frac{100}{1+10\left([I]-\log \left(\left[\mathrm{I}_{50}\right)\right) \times\right. \text { Hill slope }}
$$

For $\mathrm{EC}_{50}$ :

$$
A=100+\frac{\mathrm{A}_{\max }-100}{1+10^{\left(\log \left(\mathrm{EC}_{50}-[\mathrm{I}]\right)\right) \mathrm{x} \text { Hill slope }}}
$$

with $\mathrm{A}=$ percentage of transporter activity for a given concentration of carbamate pesticide determined as described in equation (A) (for propamocarb/OCT1/OCT2/MATE2-K) or in 
equation (B) (for chlorpropharm/BCRP), $\mathrm{A}_{\max }$ is the maximal percentage transporter activity, [I] is the carbamate pesticide concentration in the medium, and Hill slope is a coefficient describing the steepness of the curve.

\section{In silico prediction of P-gp-carbamate pesticides interactions}

Prediction of interactions of 61 carbamate pesticides with P-gp, as inhibitors and/or substrates, was performed with the web-service admetSAR 2.0 (http://lmmd.ecust.edu.cn/admetsar2/) (Yang et al., 2019), using the SMILES of pesticides, collected using the online PubChem web-site. The P-gp substrate model was built by Morgan fingerprint with support vector machine from 718 substrates and 847 non-substrates, whereas the P-gp inhibition model was built by AtomPairs fingerprint with support vector machine, from 1172 inhibitors and 771 non-inhibitors. Sensitivity, specificity and accuracy values were 0.802, 0.76 and 0.837, respectively, for P-gp substrate model, and 0.861, 0.901 and 0.8 , respectively, for the P-gp inhibition model (Yang et al., 2019). For each carbamate pesticide, the prediction (P-gp substrate or non-substrate and P-gp inhibitor or non-inhibitor) was associated with a probability value, between 0.5 to 1.0 unit; the closer the score is to 1 , the better the prediction (http://lmmd.ecust.edu.cn/admetsar2/). In silico admetSAR 2.0-based prediction of transport by $\mathrm{P}$-gp was additionally performed for reference P-gp substrates $(\mathrm{n}=10)$ and non-substrates $(\mathrm{n}=10)$, as an internal validation control.

\section{Prediction of in vivo modulation of drug transporter activity}

In vivo modulation of transporter activities by carbamate pesticides was evaluated from in vitro data using the criteria defined by the US FDA guidance on in vitro drug interaction studies (https://www.fda.gov/regulatory-information/search-fda-guidance-documents/vitrodrug-interaction-studies-cytochrome-p450-enzyme-and-transporter-mediated-druginteractions). Briefly, transporters can be in vivo inhibited by xenobiotics if the ratio 
$\mathrm{IC}_{50}$ /maximum unbound plasma concentration of chemicals $\left(\mathrm{I}_{\max , \mathrm{u}}\right) \geq 0.1$ (Giacomini et al., 2010). For prediction of potential in vivo stimulation of transporter activity, the criteria defined by the FDA was adapted by replacing $\mathrm{IC}_{50}$ by $\mathrm{EC}_{50}$. For intestinal P-gp and BCRP, they can be in vivo inhibited according to $\mathrm{FDA}$ if the ratio $\mathrm{IC}_{50} /$ luminal gut concentration $\left(\mathrm{I}_{\text {gut }}\right.$, defined by the ratio dose orally ingested/250 mL) $\geq 10$ (Giacomini et al., 2010). This criteria was also extended to intestinal OCT1 in the present study, because OCT1 is expressed at the apical membrane of enterocytes, like P-gp (Han et al., 2013). For defining the ingested oral dose of carbamate pesticides, we considered the admissible daily intake (ADI) of the pesticides, defined in the European Union-Pesticides database (https://ec.europa.eu/food/plant/pesticides/eu-pesticides-database/public); ADI values are 0.05 $\mathrm{mg} / \mathrm{kg}$ body weight and $0.29 \mathrm{mg} / \mathrm{kg}$ body weight for chlorpropham and propamocarb, respectively. These ADI values were normalised to a subject of $70 \mathrm{~kg}$ body weight and by meal; for this purpose, we postulated that the oral ingestion of the pesticide dose occurs through two daily meals, via carbamate pesticides-contaminated food and drink. This resulted in oral doses of $1.75 \mathrm{mg}(8.2 \mu$ mole $)$ and $10.15 \mathrm{mg}(53.9 \mu$ mole $)$ for chlorpropham and propamocarb, respectively, with which pesticide $I_{\text {gut }}$ values were calculated, as described above.

\section{Statistical analysis}

Experimental data were routinely expressed as means \pm SEM. They were statistically analysed through analysis of variance (ANOVA) followed by the Dunnett's or the Tukey's post-hoc test. The criterion of significance was $\mathrm{p}<0.05$. 


\section{Results}

Interactions of carbamate pesticides with ABC transporter activities

The carbamate pesticides aminocarb, carbofuran, chlorpropham and propamocarb were initially used at a non-toxic $100 \mu \mathrm{M}$ concentration, in the range of those previously used in vitro (Kawaratani et al., 2015; Yazdian et al., 2014). They failed to enhance cellular accumulation of rhodamine 123, a reference substrate for the R-site of P-gp (Jouan et al., 2016b), in P-gp overexpressing MCF7R cells (Figure 2A). In the same way, they did not alter cellular retention of Hoechst 33342, a reference substrate for the H-site of P-gp (Martinez et al., 2014). By contrast, the reference P-gp inhibitor verapamil enhanced cellular accumulation of rhodamine 123 and cellular retention of Hoechst 33342 in MCF7R cells (Figure 2A). Taken together, such data indicate that aminocarb, carbofuran, chlorpropharm and propamocarb, unlike verapamil, did not inhibit transport activity of P-gp, whatever the considered active site ( $\mathrm{R}$ or $\mathrm{H}$ ) of $\mathrm{P}$-gp. Such in vitro data were fully confirmed by in silico analysis using the admetSAR 2.0 web-tool, which predicts no inhibition of P-gp activity by these chemicals (Supplementary Table S2). In the same way, among a large set of 57 additional carbamate pesticides, 55 were predicted to not inhibit P-gp activity (Supplementary Table S2). Only alanycarb and furathiocarb were found to inhibit P-gp activity according to the in silico analysis, with, however, rather low probability values (0.6602 and 0.5935 for alanycarb and furathiocarb, respectively). Besides, P-gp was predicted to not transport aminocarb, carbofuran, chlorpropham and propamocarb, as well as the 57 additional carbamate pesticides investigated in the in silico study (Supplementary Table S2). The webtool admetSAR 2.0 was finally demonstrated to correctly in silico predict P-gp-mediated transport for various reference P-gp substrates and non-substrates, used here as positive and negative controls (Supplementary Table S3). 
Aminocarb, carbofuran, chlorpropharm and propamocarb were next found to not enhance cellular retention of the MRP substrate CDCF in HuH-7 cells, in contrast to the reference MRP inhibitor probenecid (Figure 2A). This suggests that MRP activity was not impaired by these agrochemicals. In the same way, aminocarb, carbofuran and propamocarb, unlike the reference BCRP inhibitor fumitremorgin $\mathrm{C}$, did not enhance cellular retention of the BCRP substrate Hoechst 33342 in HEK-BCRP cells (Figure 2A); this indicates a lack of effect of these carbamate pesticides towards BCRP activity. By contrast, $100 \mu \mathrm{M}$ chlorpropham significantly increased Hoechst 33342 retention in HEK-BCRP cells by a 1.5fold factor (Figure 2A), corresponding to a reduction of BCRP activity around $70 \%$, greater than the threshold of $50 \%$, retained by the US FDA for considering that a transporter inhibition may be validated (Giacomini et al., 2010). This inhibitory effect of chlorpropharm towards BCRP activity was concentration-dependent, with an $\mathrm{IC}_{50}$ value of $53.2 \mu \mathrm{M}$ (Figure 2B).

\section{Interactions of carbamate pesticides with SLC transporters of organic anions}

Aminocarb, carbofuran and propamocarb, used at $100 \mu \mathrm{M}$, did not inhibit uptake of the reference substrates DCF and 8-FcA in HEK-OATP1B1 and HEK-OATP1B3 cells (Figure 3). Aminocarb and propamocarb also failed to modify E3S accumulation in HEK-OATP2B1 cells, whereas carbofuran slightly enhanced it (Figure 3). Chlorpropham did not alter accumulation of 8-FcA in HEK-OATP1B3 cells. By contrast, it diminished accumulation of DCF in HEK-OATP1B1 cells and that of E3S in HEK-OATP2B1 cells (Figure 3); such reductions of transporter activities were however rather modest, i.e., $100 \mu \mathrm{M}$ chlorpropham decreased OATP1B1 and OATP2B1 activities by $37.2 \%$ and $24.9 \%$, respectively, thus indicating that $\mathrm{IC}_{50}$ values are higher than $100 \mu \mathrm{M}$.

Carbofuran, chlorpropham and propamocarb used at $100 \mu \mathrm{M}$ failed to decrease uptake of the reference OAT substrate 6-CF in HEK-OAT1 cells, whereas aminocarb decreased it by 
a 1.36-fold factor (Figure 4A), corresponding to a slight reduction of OAT1 activity by 28.0\%. Aminocarb, as well as carbofuran and propamocarb, similarly modestly reduced OAT3 activity, i.e., it was decreased by approximately 20-25\% (Figure 4A). By contrast, chlorpropham markedly reduced 6-CF accumulation in HEK-OAT3 cells by a 4.64-fold factor (Figure 4A), reflecting a marked repression of OAT3 activity by $91.1 \%$. Chlorpropham also hugely diminished OAT3-mediated-transport of the endogenous substrate E3S (Figure 4B). The inhibition of OAT3 activity by chlorpropham was concentration-dependent $\left(\mathrm{IC}_{50}=5.0\right.$ $\mu \mathrm{M})$ (Figure 4C). The carbamate pesticide however failed to trans- stimulate accumulation of the OAT3 substrate 6- CF in HEK- OAT3 cells (Figure 4D). By contrast, the reference OAT3 substrate glutarate trans- stimulated OAT3 activity (Figure 4D), which is fully consistent with the fact that OAT3 substrates can trans- stimulate OAT3 activity (Sweet et al., 2003).

Interactions of carbamate pesticides with SLC transporters of organic cations

Aminocarb and carbofuran failed to alter activity of OCT1, OCT2, MATE1 and MATE2-K (Figure 5A). Chlorpropharm was also without effect towards OCT1, OCT2 and MATE2-K and rather moderately decreased 4-DiASP accumulation in HEK-MATE1 cells by $33.4 \%$ (Figure 5A). Propamocarb did not alter 4-DiASP accumulation in HEK-MATE1 cells, but reduced it in HEK-OCT1 (by a 2.3-fold factor) and HEK-OCT2 cell (by a 1.9-fold factor) (Figure 5A), corresponding to repressions of OCT1 and OCT2 activity by $69.5 \%$ and $57.2 \%$, respectively. By contrast, propamocarb enhanced 4-DiASP uptake in HEK-MATE2-K cells (by a 2.4-fold factor) (Figure 5A). The inhibitory effects of propamocarb towards OCT1 and OCT2 activities were next found to be concentration-dependent, with $\mathrm{IC}_{50}$ values around 40-50 $\mu \mathrm{M}$; the cis-stimulating effect of the carbamate towards MATE2-K activity was also concentration-dependent $\left(\mathrm{EC}_{50}=5.6 \mu \mathrm{M}\right)$ (Figure 5B). Propamocarb was next demonstrated to not trans-stimulate OCT1, OCT2 or MATE2-K activity, in contrast to the reference 
substrate TEA (Figure 6A). HEK-OCT1, HEK-OCT2 and HEK-MATE2-K cells finally failed to display significant increased accumulation of propamocarb when compared to parental HEK-wt cells (Figure 6B). By contrast, HEK-OCT1, HEK-OCT2 and HEK-MATE-2K exhibited higher accumulation of the reference OCT and MATE substrate TEA comparatively to HEK-wt cells (Figure 6B).

Prediction of in vivo modulation of drug transporter activities by chlorpropham and propamocarb

Evaluation of in vivo alteration of drug transporters by chlorpropham and propamocarb was performed from in vitro data using the criteria defined by the US FDA (Giacomini et al., 2010). Plasma concentrations of pesticides in environmentally-exposed humans, although very poorly characterised, are postulated to be in the picomolar to nanomolar range (Seeger et al., 2016), and probably even less when considered their unbound fraction, which remains largely unknown. In agreement with this hypothesis, chlorpropham concentrations in 100 human blood samples collected from the general population in Beijing (China) were less than $3.8 \mathrm{nM}$ ( $\mathrm{Li}$ et al., 2018). Available plasma human concentrations for other carbamate pesticides also correspond to values in the nM range or less (Barr et al., 2010; Petropoulou et al., 2006; Whyatt et al., 2003). We therefore retained the value of $3.8 \mathrm{nM}$ as approximated $\mathrm{I}_{\max , \mathrm{u}}$ for chlorpropham and also propamocarb. With this value, most likely over-estimated due to the absence of consideration of the unbound fraction, OCT1, OCT2 and MATE2-K activities were predicted to be not in vivo impaired by plasma concentrations of propamocarb, whereas OAT3 and BCRP were similarly not predicted to be in vivo inhibited by plasma levels of chlorpropham (Table 1). For calculating luminal gut concentrations $\left(\mathrm{I}_{\text {gut }}\right)$ of chlorpropham and propamocarb, we considered the admissible daily intake (ADI) of these two pesticides according to the European Union-Pesticides database, for estimating their oral dose for one meal and a $70 \mathrm{~kg}$ body weight (Table 2 ). Although the calculated ratio $\mathrm{I}_{\text {gut }} / \mathrm{IC}_{50}$ 
reached notable levels (notably the value of 4.5 for propamocarb/OCT1), they did not fulfill the US FDA criteria for in vivo inhibiting intestinal BCRP and OCT1 (Table 2).

\section{Discussion}

The present study demonstrates that some carbamate pesticides inhibit drug transporter activities, thus adding such chemicals to the growing list of agrochemicals interacting with drug transporters. As already demonstrated for other classes of pesticides like organochlorine, pyrethroid and organophosphorus pesticides (Gueniche et al., 2020), the inhibition of transporter activity by carbamates depends on the nature of the pesticide and of the transporter. The N-methylcarbamates aminocarb and carbofuran thus rather poorly interact with $\mathrm{ABC}$ and SLC drug transporters, whereas chlorpropham inhibits BCRP and OAT3 activities and propamocarb interacts with the organic cation transporters OCT1, OCT2 and MATE2-K. The basis for such differential interactions of carbamate pesticides with drug transporters is most likely due to the specific physicochemical features of each carbamate agrochemical, as already described for pyrethroid or organophosphorus pesticides (Chedik et al., 2019; Chedik et al., 2017a). The reduced number of carbamate pesticides analysed in the present study, i.e., only four carbamate pesticides, unfortunately prevents to search the physicochemical parameters which may discriminate inhibitors from non-inhibitors among this pesticide class.

None of the four carbamate pesticides analysed in the present study was found to inhibit P-gp activity, whatever the considered active site of P-gp (R- or H-site). Similarly, the carbamate pesticides aldoxycarb, carbaryl, lannate and propoxur used at 100 or $250 \mu \mathrm{M}$ failed to inhibit P-gp activity in P-gp-expressing cultured cells (Bain and LeBlanc, 1996). Taken together, such data suggest that no or little inhibitory effects towards P-gp can be expected for carbamate pesticides. Results from P-gp inhibition prediction with an in silico web-tool for a large set of carbamate pesticides fully argue in favor of this hypothesis. Indeed, only $2 / 61$ 
carbamate pesticides, i.e., alanycarb and furathiocarb, were predicted to inhibit P-gp, with moreover rather low probability values. Carbamate pesticides were additionally predicted to be not substrates for P-gp. A P-gp-mediated efflux of carbamate pesticides at the apical pole of enterocytes can therefore likely be discarded, which fully agrees with the predicted high intestinal absorption of these agrochemicals (Chedik et al., 2017b). Transport of carbamate pesticides by P-gp expressed at the apical pole of capillary brain endothelial cells (CordonCardo et al., 1989) can similarly most likely be ruled out; this may suggest a high passage of carbamate pesticides across the blood-brain barrier and agrees with their predicted high brain permeation (Chedik et al., 2017b). Besides P-gp activity, those of MRPs and BCRP were also not impacted by the carbamate pesticides used in the present study, excepted chlorpropham, which inhibited BCRP. The lack of inhibition of human BCRP by propamocarb does not agree with previous data reporting an inhibition of rabbit BCRP activity by this carbamate pesticide (Halwachs et al., 2016). Such a discrepancy may be due to the use of different concentrations of propamocarb in the studies $(100 \mu \mathrm{M}$ in our present study and $265.5 \mu \mathrm{M}$ in that of Halwach et al. (2016)). Alternatively, it may reflect species-dependent effects of propamocarb towards BCRP activity; such a concept of species-dependent inhibition of transporters is already established for at least P-gp (Zolnerciks et al., 2011).

It is noteworthy that inhibition of transporters by chlorpropham and propamocarb is unlikely to occur in environmentally-exposed humans when applying the criteria of FDA for in vivo drug-drug interactions due to impairment of transporter activities. This reflects the fact that in vitro inhibition of drug transporters requires rather high concentrations of carbamate pesticides ( $\mathrm{IC}_{50}$ values are approximately in the $5-50 \mu \mathrm{M}$ range), whereas their human plasma unbound concentrations, although very poorly characterised, may be postulated to be much lower, i.e., in the $\mathrm{nM}$ range or $\mathrm{pM}$ range. Luminal gut concentrations of chlorpropham and propamocarb, although in the $30-200 \mu \mathrm{M}$ range for oral ingestion of the ADI dose, are also 
insufficient for inhibiting in vivo intestinal BCRP or OCT1. Other pesticides interacting with drug transporters in cultured cells, such as the pyrethoids allethrin and tetramethrin and some organophosphorus pesticides, have similarly been hypothesised to fail to alter transporter activities in environmentally- or occupationally-exposed humans (Chedik et al., 2019; Chedik et al., 2017a; Gueniche et al., 2020). It should however be kept in mind that humans are often exposed to mixtures of pesticides and/or other environmental pollutants like plasticizers, whose inhibitory effects towards drug transporters may add or synergize, as already demonstrated for inhibition of P-gp by pesticide combinations (Pivcevic and Zaja, 2006) or marine pollutants (Nicklisch et al., 2016). Exposure to such mixtures may consequently have to be considered for judging the in vivo relevance of transporter inhibition by pollutants, including carbamate pesticides (Gueniche et al., 2020). This assertion may be notably valuable for agricultural workers, often exposed to high concentrations of pesticides in an occupational manner (Mostafalou and Abdollahi, 2017). Besides, human poisoning by carbamate pesticides, either accidentally or by self-ingestion, can result in relative high in vivo concentrations of these agrochemicals, reaching the $\mu \mathrm{M}$ range (Michael et al., 2015; Moriya and Hashimoto, 2005) and thus putatively blocking transporter activities. The potential clinical consequences of such inhibitions of drug transporters are nevertheless most likely completely overshadowed by the severe cholinergic crisis characterizing carbamate insecticide poisoning (Vale and Lotti, 2015). Carbamate poisoning also concerns domestic animals, such as cats and dogs (de Siqueira et al., 2015), for which inhibition of transporters by carbamates may consequently be hypothesized to also occur.

Propamocarb was able to cis-stimulate MATE2-K activity and such a stimulation of drug transporter activity, although not frequent, has also been reported to occur for OATP2B1 activity in response to organophosphorus pesticides (Chedik et al., 2019). In the same way, some drugs have demonstrated to cis-stimulate activity of transporters; for example, the 
hypoglycemic drug glibenclamide and the non-steroidal anti-inflammatory agent indomethacin enhanced activity of the ABC pump MRP2 (Pedersen et al., 2008), whereas that of OATP2B1 is increased by rifampicin (Vildhede et al., 2014). The molecular mechanism of such transporter cis-stimulations and the potential consequences, notably for intestinal absorption of xenobiotics, remain to be determined (Ogura et al., 2014).

Chloropropham failed to trans-stimulate activity of OAT3, whereas those of OCT1, OCT2 and MATE2-K were similarly not trans-stimulated by propamocarb. Because substrates are considered to trans-stimulate such transporters (Sweet et al., 2003; Zhang et al., 1999), these data indicate that chlorpropham and propamocarb are likely not transported, or only poorly, by these transporters. The fact that HEK-OCT1, HEK-OCT2 and HEK-MATE2K cells did not exhibit significant enhanced accumulation of propamocarb when compared to parental HEK-wt cells supports this conclusion. OAT3, expressed at the basolateral pole of proximal tubular cells (Burckhardt, 2012), is therefore unlikely to be implicated in the preferential accumulation of chlorpropham in the kidney and in its renal excretion, described in rats (Fang et al., 1974). In the same way, the renal transporters OCT2 and MATE2-K (Motohashi and Inui, 2013) are unlikely to participate to the major elimination of propamocarb by the kidney (Kopp et al., 1979), whereas intestinal OCT1 probably fails to contribute to the intestinal absorption of this pesticide.

In summary, the herbicide carbamate chlorpropham as well as the fungicide carbamate propamocarb were found to in vitro interact with some drug transporters. Chlorpropham inhibited BCRP and OAT3 activities, whereas propamocarb impaired those of OCT1, OCT2 and MATE-2K, without being transported. Chlorpropham and propamocarb concentrations required for interactions with transporters are however much higher than those expected in environmentally-exposed humans, making unlikely in vivo transporter activity alterations by these carbamate pesticides as single agents. The fact that chlorpropham and propamocarb 
effects towards transporters may add on or synergize with those of other pesticides and/or chemicals contaminants, to which humans are often co-exposed in an environmental or occupational context, has however probably to be considered.

\section{Acknowledgements}

The authors thanks Dr Y. Parmentier, Dr C. Denizot and Dr M. Le Vée for helpful support with HEK-293 cell clones overexpressing transporters and Technologie Servier (Orléans, France) for the gift of the LC-MS/MS system.

\section{Disclosure statement}

No potential conflict of interest was reported by the authors.

\section{References}

Ayrton A, Morgan P. (2001). Role of transport proteins in drug absorption, distribution and excretion. Xenobiotica, 31, 469-97.

Bain LJ, LeBlanc GA. (1996). Interaction of structurally diverse pesticides with the human MDR1 gene product P-glycoprotein. Toxicol Appl Pharmacol, 141, 288-98.

Barr DB, Ananth CV, Yan X, Lashley S, Smulian JC, Ledoux TA, Hore P, Robson MG. (2010). Pesticide concentrations in maternal and umbilical cord sera and their relation to birth outcomes in a population of pregnant women and newborns in New Jersey. Sci Total Enyiron, 408, 790-5.

Bouvier G, Blanchard O, Momas I, Seta N. (2006). Pesticide exposure of non-occupationally exposed subjects compared to some occupational exposure: a French pilot study. Sci Total Environ, 366, 74-91. 
Bouvier G, Seta N, Vigouroux-Villard A, Blanchard O, Momas I. (2005). Insecticide urinary metabolites in nonoccupationally exposed populations. J Toxicol Environ Health B Crit Rev, 8, 485-512.

Bradford MM. (1976). A rapid and sensitive method for the quantitation of microgram quantities of protein utilizing the principle of protein-dye binding. Anal Biochem, 72, 248-54.

Bucher S, Le Vee M, Jouan E, Fardel O. (2014). Regulation of hepatic drug transporter activity and expression by organochlorine pesticides. J Biochem Mol Toxicol, 28, 11928.

Burckhardt G. (2012). Drug transport by Organic Anion Transporters (OATs). Pharmacol Ther, 136, 106-30.

Buss DS, Callaghan A. (2008). Interaction of pesticides with p-glycoprotein and other ABC proteins: A survey of the possible importance to insecticide, herbicide and fungicide resistance. Pesticide Biochemistry and Physiology, 90, 141-53.

Chedik L, Bruyere A, Bacle A, Potin S, Le Vee M, Fardel O. (2018). Interactions of pesticides with membrane drug transporters: implications for toxicokinetics and toxicity. Expert Opin Drug Metab Toxicol, 14, 739-52.

Chedik L, Bruyere A, Fardel O. (2019). Interactions of organophosphorus pesticides with solute carrier (SLC) drug transporters. Xenobiotica, 49, 363-74.

Chedik L, Bruyere A, Le Vee M, Stieger B, Denizot C, Parmentier Y, Potin S, Fardel O. (2017a). Inhibition of human drug transporter activities by the pyrethroid pesticides allethrin and tetramethrin. PLoS One, 12, e0169480.

Chedik L, Mias-Lucquin D, Bruyere A, Fardel O. (2017b). In silico prediction for intestinal absorption and brain penetration of chemical pesticides in humans. Int $\mathbf{J}$ Environ Res Public Health, 14, pii: E708.

Chen Y, Zhang S, Sorani M, Giacomini KM. (2007). Transport of paraquat by human organic cation transporters and multidrug and toxic compound extrusion family. J Pharmacol Exp Ther, 322, 695-700. 
Clerbaux LA, Paini A, Lumen A, Osman-Ponchet H, Worth AP, Fardel O. (2019). Membrane transporter data to support kinetically-informed chemical risk assessment using nonanimal methods: Scientific and regulatory perspectives. Environ Int, 126, 659-71.

Cordon-Cardo C, O'Brien JP, Casals D, Rittman-Grauer L, Biedler JL, Melamed MR, Bertino JR. (1989). Multidrug-resistance gene (P-glycoprotein) is expressed by endothelial cells at blood-brain barrier sites. Proc Natl Acad Sci U S A, 86, 695-8.

de Siqueira A, Salvagni FA, Yoshida AS, Goncalves-Junior V, Calefi AS, Fukushima AR, Spinosa Hde S, Maiorka PC. (2015). Poisoning of cats and dogs by the carbamate pesticides aldicarb and carbofuran. Res Vet Sci, 102, 142-9.

Dhouib I, Jallouli M, Annabi A, Marzouki S, Gharbi N, Elfazaa S, Lasram MM. (2016). From immunotoxicity to carcinogenicity: the effects of carbamate pesticides on the immune system. Environ Sci Pollut Res Int, 23, 9448-58.

Fang SC, Fallin E, Montgomery ML, Freed VH. (1974). Metabolic studies of C-14-labelled propham and chlorpropham in female rat. Pesticide Biochemistry and Physiology, 4, 111.

Fardel O, Kolasa E, Le Vee M. (2012). Environmental chemicals as substrates, inhibitors or inducers of drug transporters: implication for toxicokinetics, toxicity and pharmacokinetics. Expert Opin Drug Metab Toxicol, 8, 29-46.

Giacomini KM, Huang SM, Tweedie DJ, Benet LZ, Brouwer KL, Chu X, Dahlin A, Evers R, Fischer V, Hillgren KM and others. (2010). Membrane transporters in drug development. Nat Rev Drug Discov, 9, 215-36.

Griffin J, Fletcher N, Clemence R, Blanchflower S, Brayden DJ. (2005). Selamectin is a potent substrate and inhibitor of human and canine P-glycoprotein. J Vet Pharmacol Ther, 28, 257-65.

Gueniche N, Bruyere A, Le Vee M, Fardel O. (2020). Implication of human drug transporters to toxicokinetics and toxicity of pesticides. Pest Manag Sci, 76, 18-25.

Halwachs S, Schafer I, Kneuer C, Seibel P, Honscha W. (2016). Assessment of ABCG2mediated transport of pesticides across the rabbit placenta barrier using a novel MDCKII in vitro model. Toxicol Appl Pharmacol, 305, 66-74. 
Han TK, Everett RS, Proctor WR, Ng CM, Costales CL, Brouwer KL, Thakker DR. (2013). Organic cation transporter 1 (OCT1/mOct1) is localized in the apical membrane of Caco-2 cell monolayers and enterocytes. Mol Pharmacol, 84, 182-9.

Jouan E, Le Vee M, Denizot C, Parmentier Y, Fardel O. (2016a). Drug transporter expression and activity in human hepatoma HuH-7 cells. Pharmaceutics, 9, pii: E3.

Jouan E, Le Vee M, Mayati A, Denizot C, Parmentier Y, Fardel O. (2016b). Evaluation of Pglycoprotein inhibitory potential using a Rhodamine 123 accumulation assay. Pharmaceutics, 8, pii: E12.

Kawaratani Y, Matsuoka T, Hirata Y, Fukata N, Nagaoka Y, Uesato S. (2015). Influence of the carbamate fungicide benomyl on the gene expression and activity of aromatase in the human breast carcinoma cell line MCF-7. Environ Toxicol Pharmacol, 39, 292-9.

Konig J, Muller F, Fromm MF. (2013). Transporters and drug-drug interactions: important determinants of drug disposition and effects. Pharmacol Rev, 65, 944-66.

Kopp R, Humpel M, Kühne G, Aner B, Klawa D, Rzadkiewicz M, Milhous WK, Davidson DE, Jr. (1979). Pharmacokinetics of propamocarb hydrochloride on single and repeated oral administration of $0.5 \mathrm{mg} / \mathrm{kg}$ in rats. Submitted to WHO, unpublished report from Schering AG.

Le Vee M, Bacle A, Bruyere A, Fardel O. (2019). Neonicotinoid pesticides poorly interact with human drug transporters. J Biochem Mol Toxicol, 33, e22379.

Li J, Wang P, Shi S, Xue J. (2018). Background biomonitoring of residue levels of 137 pesticides in the blood plasma of the general population in Beijing. Environ Monit Assess, 190, 315.

Liu X. (2019). Transporter-mediated drug-drug interactions and their significance. Adv Exp Med Biol, 1141, 241-91.

Martinez L, Arnaud O, Henin E, Tao H, Chaptal V, Doshi R, Andrieu T, Dussurgey S, Tod M, Di Pietro A and others. (2014). Understanding polyspecificity within the substratebinding cavity of the human multidrug resistance P-glycoprotein. FEBS J, 281, 673-82.

Michael AP, Mostafa A, Cooper JM, Grice J, Roberts MS, Isbister GK. (2015). The pharmacokinetics and pharmacodynamics of severe aldicarb toxicity after overdose. Clin Toxicol (Phila), 53, 633-5. 
Miranda-Contreras L, Gomez-Perez R, Rojas G, Cruz I, Berrueta L, Salmen S, Colmenares M, Barreto S, Balza A, Zavala L and others. (2013). Occupational exposure to organophosphate and carbamate pesticides affects sperm chromatin integrity and reproductive hormone levels among Venezuelan farm workers. J Occup Health, 55, 195-203.

Moriya F, Hashimoto Y. (2005). A fatal poisoning caused by methomyl and nicotine. Forensic Sci Int, 149, 167-70.

Mostafalou S, Abdollahi M. (2017). Pesticides: an update of human exposure and toxicity. Arch Toxicol, 91, 549-99.

Motohashi H, Inui K. (2013). Organic cation transporter OCTs (SLC22) and MATEs (SLC47) in the human kidney. AAPS J, 15, 581-8.

Nicklisch SC, Rees SD, McGrath AP, Gokirmak T, Bonito LT, Vermeer LM, Cregger C, Loewen G, Sandin S, Chang G and others. (2016). Global marine pollutants inhibit Pglycoprotein: Environmental levels, inhibitory effects, and cocrystal structure. Sci Adv, 2, e1600001.

Nigam SK. (2015). What do drug transporters really do? Nat Rev Drug Discov, 14, 29-44.

Ogura J, Koizumi T, Segawa M, Yabe K, Kuwayama K, Sasaki S, Kaneko C, Tsujimoto T, Kobayashi M, Yamaguchi H and others. (2014). Quercetin-3-rhamnoglucoside (rutin) stimulates transport of organic anion compounds mediated by organic anion transporting polypeptide 2B1. Biopharm Drug Dispos, 35, 173-82.

Patel S, Sangeeta S. (2019). Pesticides as the drivers of neuropsychotic diseases, cancers, and teratogenicity among agro-workers as well as general public. Environ Sci Pollut Res Int, 26, 91-100.

Pedersen JM, Matsson P, Bergstrom CA, Norinder U, Hoogstraate J, Artursson P. (2008). Prediction and identification of drug interactions with the human ATP-binding cassette transporter multidrug-resistance associated protein 2 (MRP2; ABCC2). J Med Chem, $51,3275-87$.

Petropoulou SS, Tsarbopoulos A, Siskos PA. (2006). Determination of carbofuran, carbaryl and their main metabolites in plasma samples of agricultural populations using gas chromatography-tandem mass spectrometry. Anal Bioanal Chem, 385, 1444-56. 
Piel C, Pouchieu C, Carles C, Beziat B, Boulanger M, Bureau M, Busson A, Gruber A, Lecluse Y, Migault L and others. (2019). Agricultural exposures to carbamate herbicides and fungicides and central nervous system tumour incidence in the cohort AGRICAN. Environ Int, 130, 104876.

Pivcevic B, Zaja R. (2006). Pesticides and their binary combinations as P-glycoprotein inhibitors in NIH 3T3/MDR1 cells. Environ Toxicol Pharmacol, 22, 268-76.

Sayyed K, Le Vee M, Abdel-Razzak Z, Fardel O. (2017). Inhibition of organic anion transporter (OAT) activity by cigarette smoke condensate. Toxicol In Vitro, 44, 27-35.

Seeger B, Klawonn F, Nguema Bekale B, Steinberg P. (2016). Mixture effects of estrogenic pesticides at the human estrogen receptor alpha and beta. PLoS One, 11, e0147490.

Song IS, Jeong HU, Choi MK, Kwon M, Shin Y, Kim JH, Lee HS. (2020). Interactions between cyazofamid and human drug transporters. J Biochem Mol Toxicol, e22459.

Sweet DH, Chan LM, Walden R, Yang XP, Miller DS, Pritchard JB. (2003). Organic anion transporter 3 (Slc22a8) is a dicarboxylate exchanger indirectly coupled to the $\mathrm{Na}+$ gradient. Am J Physiol Renal Physiol, 284, F763-9.

Tournier N, Chevillard L, Megarbane B, Pirnay S, Scherrmann JM, Decleves X. (2010). Interaction of drugs of abuse and maintenance treatments with human P-glycoprotein (ABCB1) and breast cancer resistance protein (ABCG2). Int J Neuropsychopharmacol, $13,905-15$

Vale A, Lotti M. (2015). Organophosphorus and carbamate insecticide poisoning. Handb Clin Neurol, 131, 149-68.

Vildhede A, Karlgren M, Svedberg EK, Wisniewski JR, Lai Y, Noren A, Artursson P. (2014). Hepatic uptake of atorvastatin: influence of variability in transporter expression on uptake clearance and drug-drug interactions. Drug Metab Dispos, 42, 1210-8.

Whyatt RM, Barr DB, Camann DE, Kinney PL, Barr JR, Andrews HF, Hoepner LA, Garfinkel R, Hazi Y, Reyes A and others. (2003). Contemporary-use pesticides in personal air samples during pregnancy and blood samples at delivery among urban minority mothers and newborns. Environ Health Perspect, 111, 749-56. 
Wright SH, Wunz TM. (1988). Mechanism of cis- and trans-substrate interactions at the tetraethylammonium/H+ exchanger of rabbit renal brush-border membrane vesicles. $\mathrm{J}$ Biol Chem, 263, $19494-7$.

Yang H, Lou C, Sun L, Li J, Cai Y, Wang Z, Li W, Liu G, Tang Y. (2019). admetSAR 2.0: web-service for prediction and optimization of chemical ADMET properties. Bioinformatics, 35, 1067-9.

Yazdian S, Fahham N, Ghahremani MH, Afzali M, Farsandaj N, Vatankhah M, Ostad SN. (2014). Evaluation of the expression of P-glycoprotein in propoxur-resistant Caco-2 cells. Acta Med Iran, 52, 728-33.

Zhang L, Gorset W, Dresser MJ, Giacomini KM. (1999). The interaction of ntetraalkylammonium compounds with a human organic cation transporter, hOCT1. J Pharmacol Exp Ther, 288, 1192-8.

Zolnerciks JK, Booth-Genthe CL, Gupta A, Harris J, Unadkat JD. (2011). Substrate- and species-dependent inhibition of P-glycoprotein-mediated transport: implications for predicting in vivo drug interactions. J Pharm Sci, 100, 3055-61. 
<smiles>CNC(=O)Oc1ccc(N(C)C)c(C)c1</smiles>

Aminocarb<smiles>CC(C)OC(=O)Nc1cccc(Cl)c1</smiles>

Chlorpropham<smiles>CNC(=O)Oc1cccc2c1OC(C)(C)C2</smiles>

Carbofuran<smiles>CCCOC(=O)NCC[C@H](C)N(C)C</smiles>

Propamocarb

Figure 1. Chemical structures of carbamate pesticides. 
A

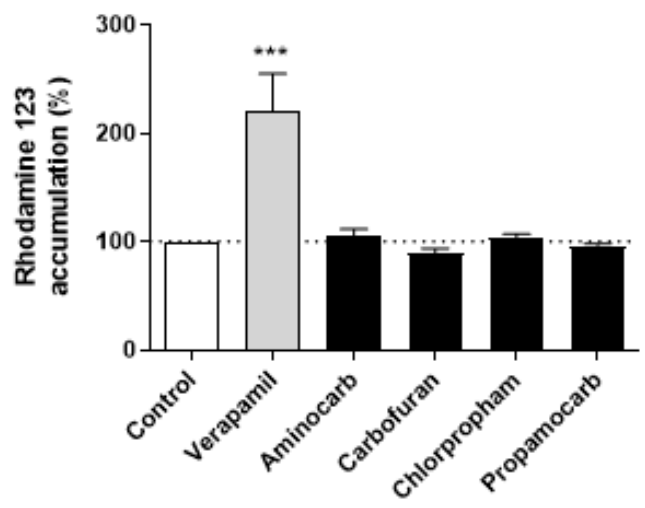

HuH-7 cells

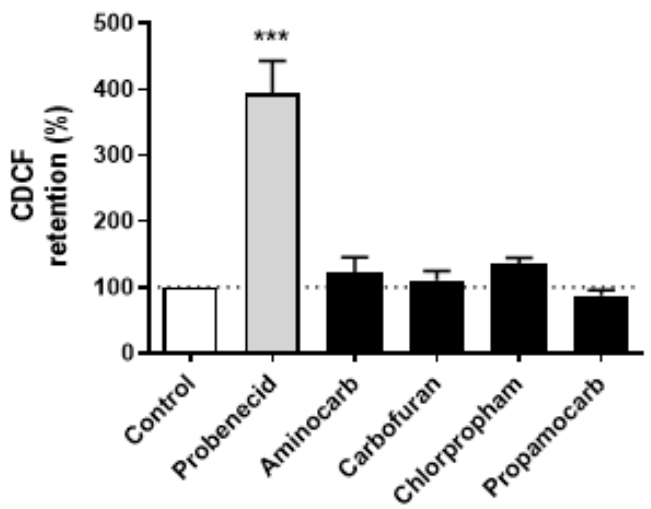

B

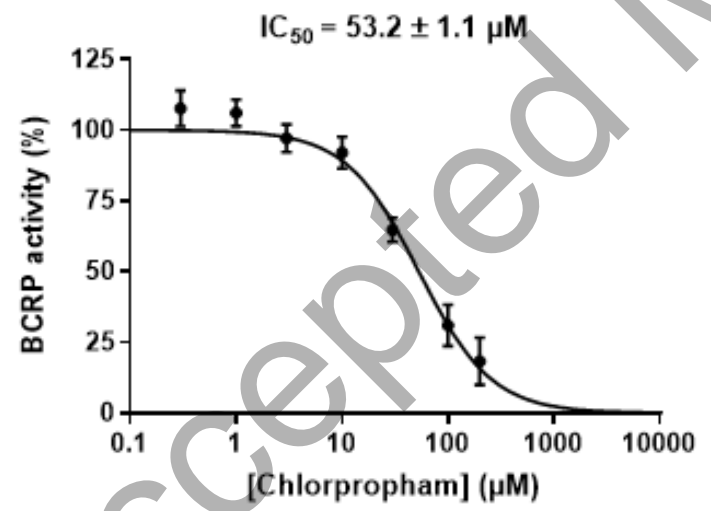

MCF7-R cells

(P-gp: H-site)

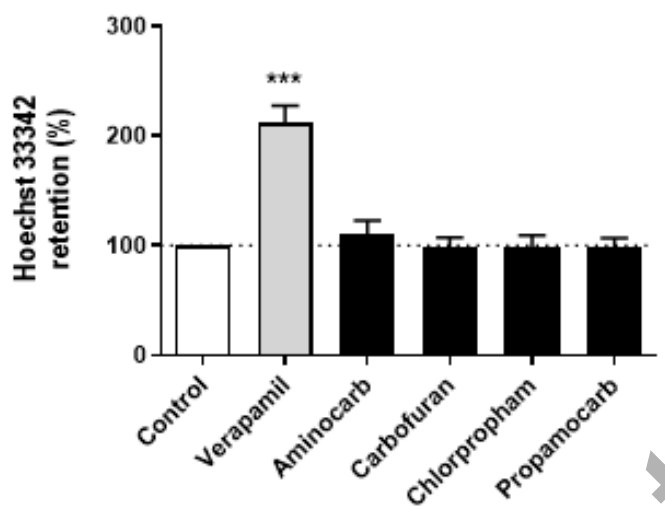

HEK-BCRP cells

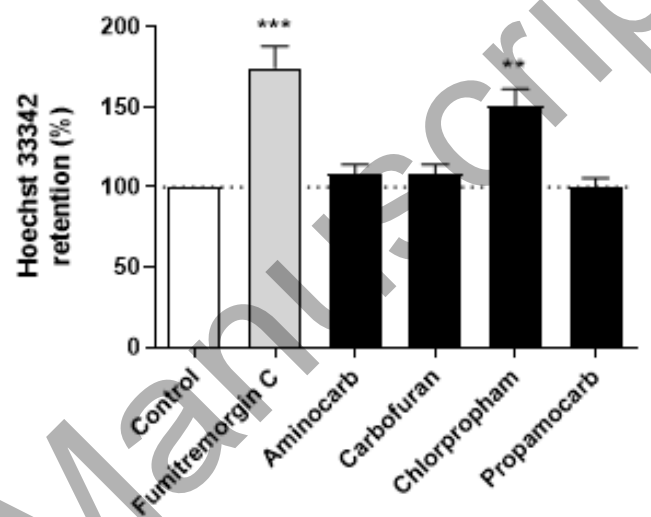

Figure 2. Effects of carbamate pesticides on P-gp, MRP and BCRP activities.

(A) Accumulation or retention of reference substrates for P-gp (rhodamine 123 and Hoechst 33342), MRPs (CDCF) or BCRP (Hoechst 33342) in P-gp-expressing MCF7R cells, MRPs- 
expressing HuH-7 cells or HEK-BCRP cells were determined in the absence (control) or the presence of $100 \mu \mathrm{M}$ carbamate pesticides or reference inhibitors (100 $\mu \mathrm{M}$ verapamil for P-gp, $2 \mathrm{mM}$ probenecid for MRPs or $10 \mu \mathrm{M}$ fumitremorgin $\mathrm{C}$ for BCRP). Data are expressed as $\%$ of substrate accumulation or retention in control cells; they are the means \pm SEM of at least three independent assays. Dotted lines indicate substrate levels in control cells. ${ }^{* *}, \mathrm{p}<0.01$ and $* * *, p<0.001$ when compared to control. (B) Effects of various concentrations of chlorpropham on BCRP activity, i.e., Hoechst 33342 transport, were analysed in HEK-BCRP cells. Data are expressed as \% of BCRP activity in control cells not exposed to chlorpropham, arbitrarily set at $100 \%$; they are the means \pm SEM of five independent assays. IC $_{50}$ value of chlorpropham is indicated at the top of the graph. 

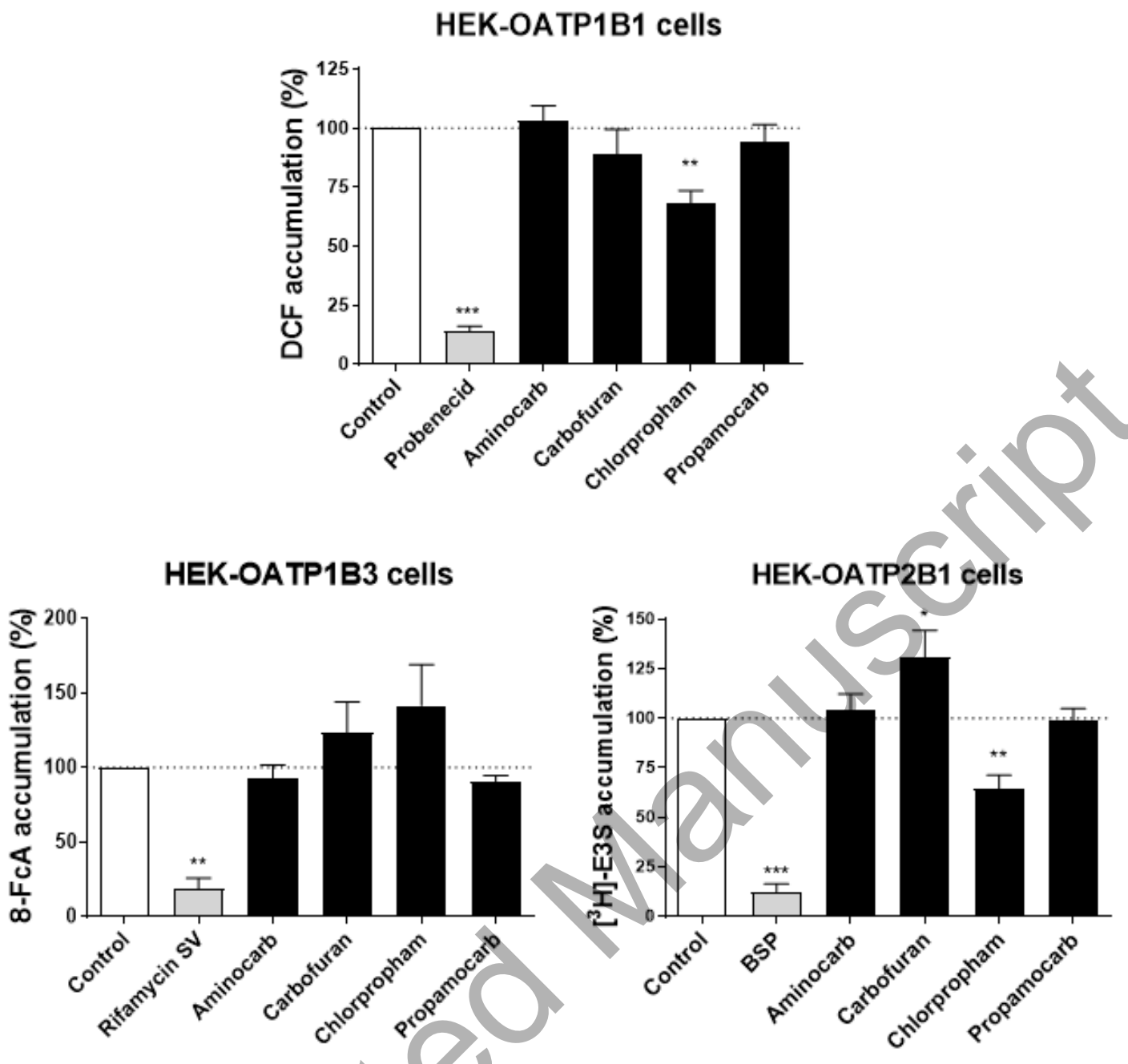

Figure 3. Effects of carbamate pesticides on OATP activities.

Accumulation of reference substrates for OATP1B1 (DCF), OATP1B3 (8-FcA) or OATP2B1 $\left(\left[{ }^{3} \mathrm{H}\right]-\mathrm{E} 3 \mathrm{~S}\right)(\mathrm{C})$ in HEK-OATP1B1, HEK-OATP1B3 or HEK-OATP2B1 cells was determined 
in the absence (control) or the presence of $100 \mu \mathrm{M}$ carbamate pesticides or reference inhibitors $(2 \mathrm{mM}$ probenecid for OATP1B1, $100 \mu \mathrm{M}$ rifamycin SV for OATP1B3 or $100 \mu \mathrm{M}$ BSP for OATP2B1). Data are expressed as \% of reference substrate accumulation in control cells; they are the means \pm SEM of at least three independent assays. Dotted lines indicate the reference substrate levels in control cells. ${ }^{*}, \mathrm{p}<0.05, * *, \mathrm{p}<0.01$ and $* * *, \mathrm{p}<0.001$ when compared to control. 
A

HEK-OAT1 cells

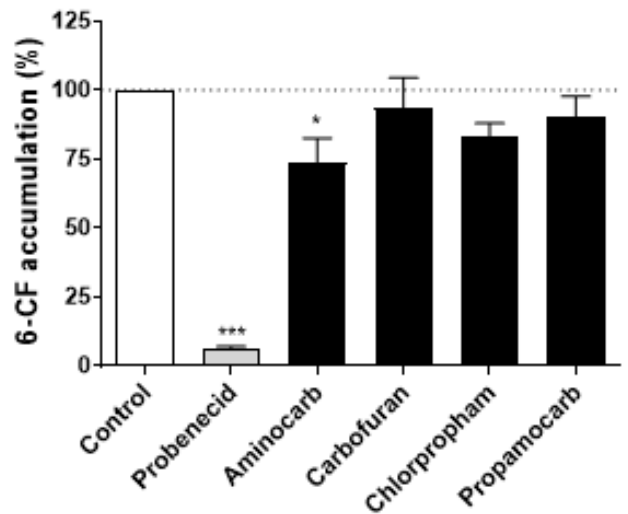

B

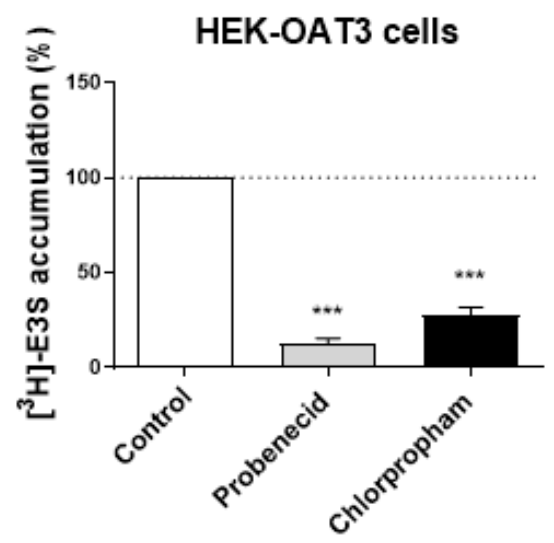

D

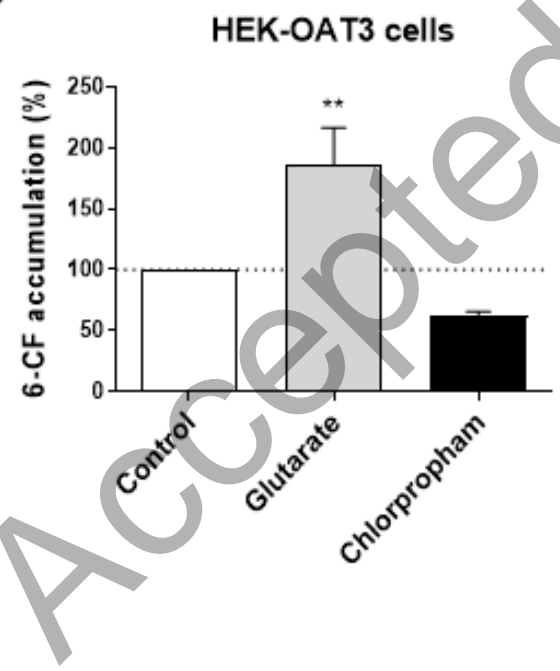

HEK-OAT3 cells

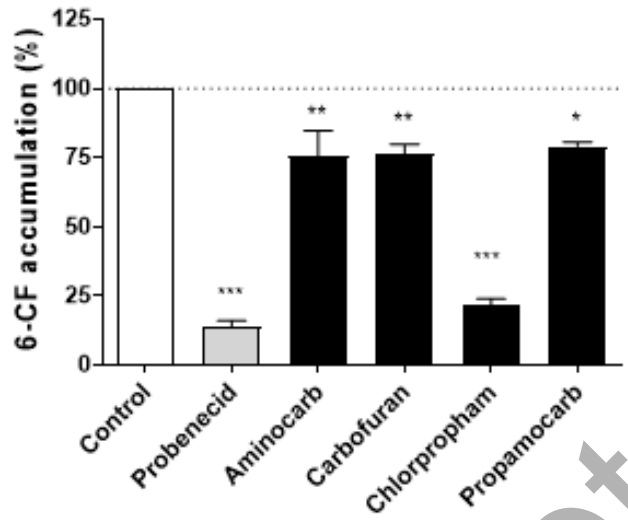

C

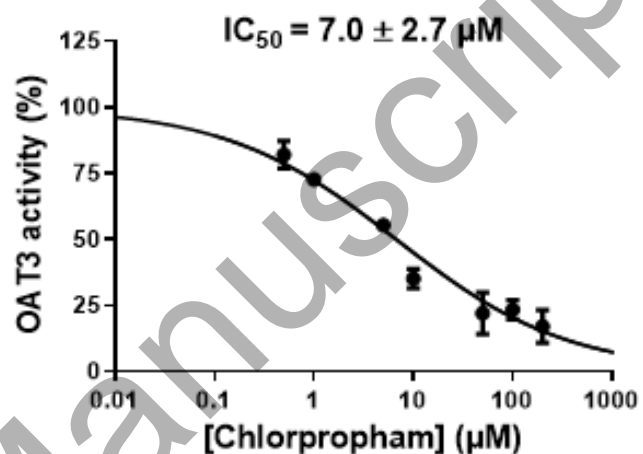

Figure 4. Interactions of carbamate pesticides with OAT1 and OAT3.

(A) Accumulation of the reference OAT1/3 substrate 6-CF in HEK-OAT1 or HEK-OAT3 cells was determined in the absence (control) or the presence of $100 \mu \mathrm{M}$ carbamate pesticides or 
the reference OAT1/3 inhibitor probenecid (used at $2 \mathrm{mM}$ ). Data are expressed as $\%$ of $6-\mathrm{CF}$ accumulation in control cells and are the means \pm SEM of at least four independent assays. Dotted lines indicate 6-CF levels in control cells. *, $\mathrm{p}<0.05,{ }^{* *}, \mathrm{p}<0.01$ and ***, $\mathrm{p}<0.001$ when compared to control. (B) Accumulation of the reference OAT3 substrate $\left[{ }^{3} \mathrm{H}\right]-\mathrm{E} 3 \mathrm{~S}$ in HEK-OAT3 cells was determined in the absence (control) or the presence of $100 \mu \mathrm{M}$ chlorpropham or $2 \mathrm{mM}$ probenecid. Data are expressed as $\%$ of $\left[{ }^{3} \mathrm{H}\right]-\mathrm{E} 3 \mathrm{~S}$ accumulation in control cells and are the means \pm SEM of three independent assays. The dotted line indicates $\left[{ }^{3} \mathrm{H}\right]$-E3S levels in control cells. ***, $\mathrm{p}<0.001$ when compared to control. (C) Effects of various concentrations of chlorpropham on OAT3 activity, i.e., 6-CF transport, were analysed in HEK-OAT3 cells. Data are expressed as \% of OAT3 activity in control cells not exposed to chlorpropham, arbitrarily set at $100 \%$; they are the means \pm SEM of three independent assays. $\mathrm{IC}_{50}$ value of chlorpropham is indicated at the top of the graph. (D) Trans-stimulating effect of $100 \mu \mathrm{M}$ chlorpropham or $1 \mathrm{mM}$ glutarate towards OAT3-mediated uptake of 6-CF was determined in HEK-OAT3 cells. Data are expressed as \% of 6-CF accumulation in control cells, arbitrarily set at $100 \%$, and are the means \pm SEM of three assays. The dotted line indicates 6-CF levels in control cells. **, $\mathrm{p}<0,01$ when compared to control. 
A

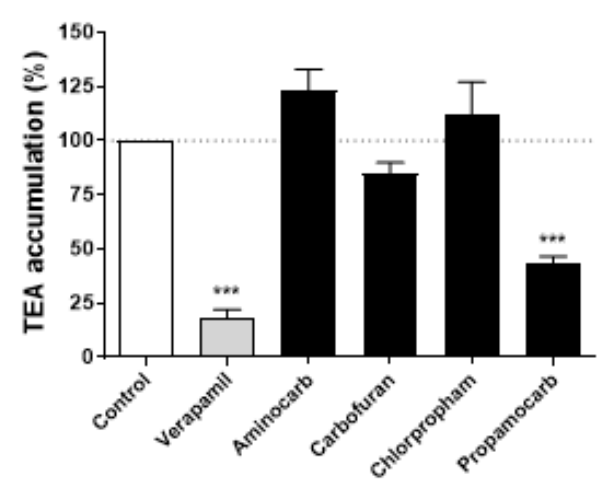

HEK-MATE1 cells

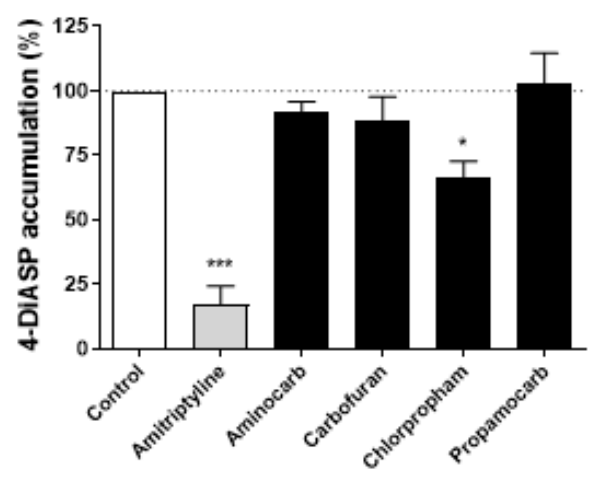

B

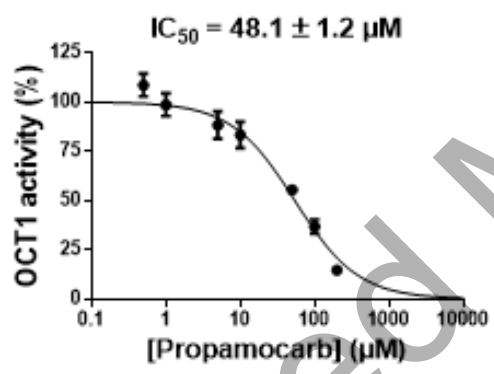

HEK-OCT2 cells

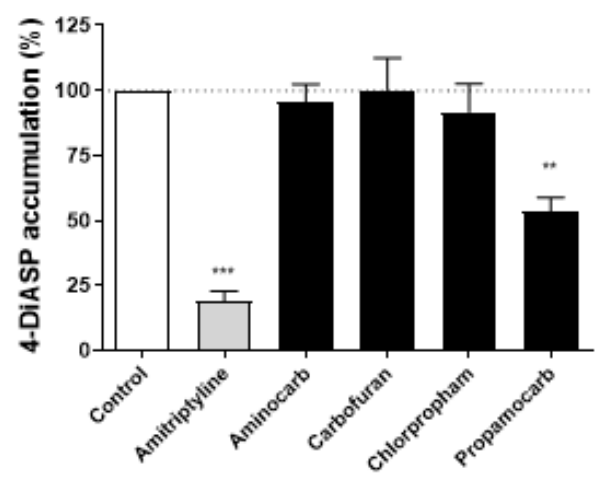

HEK-MATE2-K cells
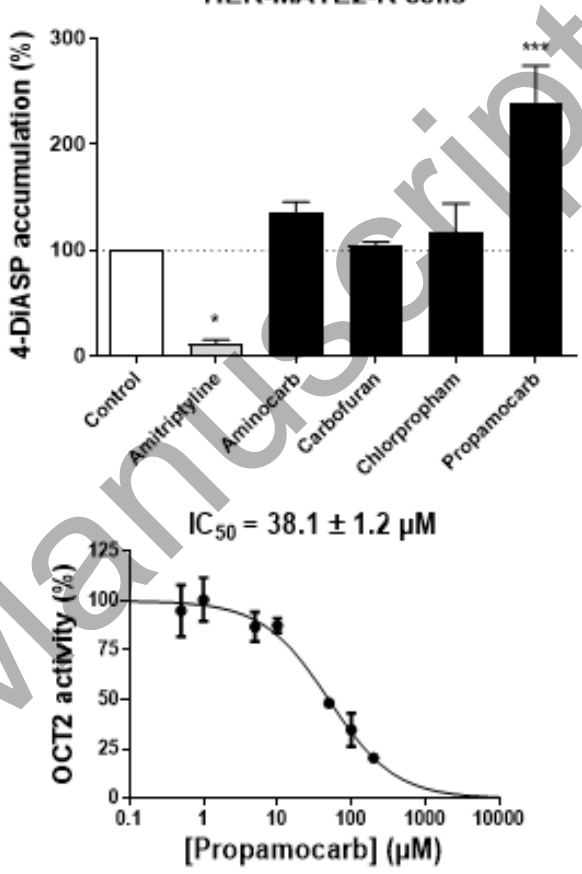

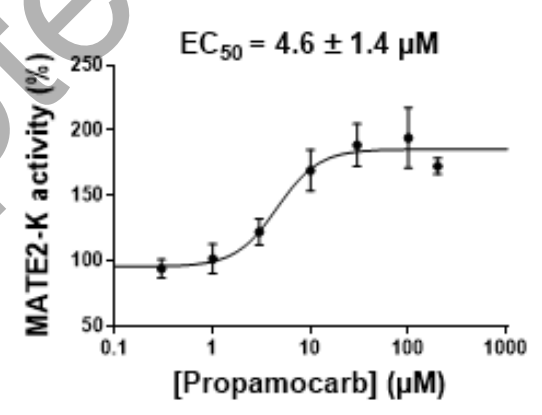

Figure 5. Effects of carbamate pesticides on OCT and MATE activities. 
(A) Accumulation of reference substrates for OCT1 (TEA) or for OCT2, MATE1 and MATE2-K (4-DiASP) in HEK-OCT1, HEK-OCT2, HEK-MATE1 or HEK-MATE2-K cells was determined in the absence (control) or the presence of $100 \mu \mathrm{M}$ carbamate pesticides or reference inhibitors $(200 \mu \mathrm{M}$ verapamil for OCT1 or $100 \mu \mathrm{M}$ amitriptyline for OCT2, MATE1 or MATE2-K). Data are expressed as \% of reference substrate accumulation in control cells; they are the means \pm SEM of at least three independent assays. Dotted lines indicate the reference substrate levels in control cells. ${ }^{*}, \mathrm{p}<0.05, * *, \mathrm{p}<0.01$ and ${ }^{* * *}, \mathrm{p}<$ 0.001 when compared to control. (B) Effects of various concentrations of propamocarb on OCT1, OCT2 or MATE2-K activity were analysed through determining accumulation of TEA (OCT1 activity) or 4-DiASP (OCT2 or MATE2-K activity) in HEK-OCT1, HEK-OCT2 or HEK-MATE2-K cells. Data are expressed as \% of transporter activity in control cells not exposed to propamocarb, arbitrarily set at $100 \%$; they are the means \pm SEM of at least three independent assays. $\mathrm{IC}_{50}$ or $\mathrm{EC}_{50}$ values of propamocarb are indicated at the top of the graphs. 
A
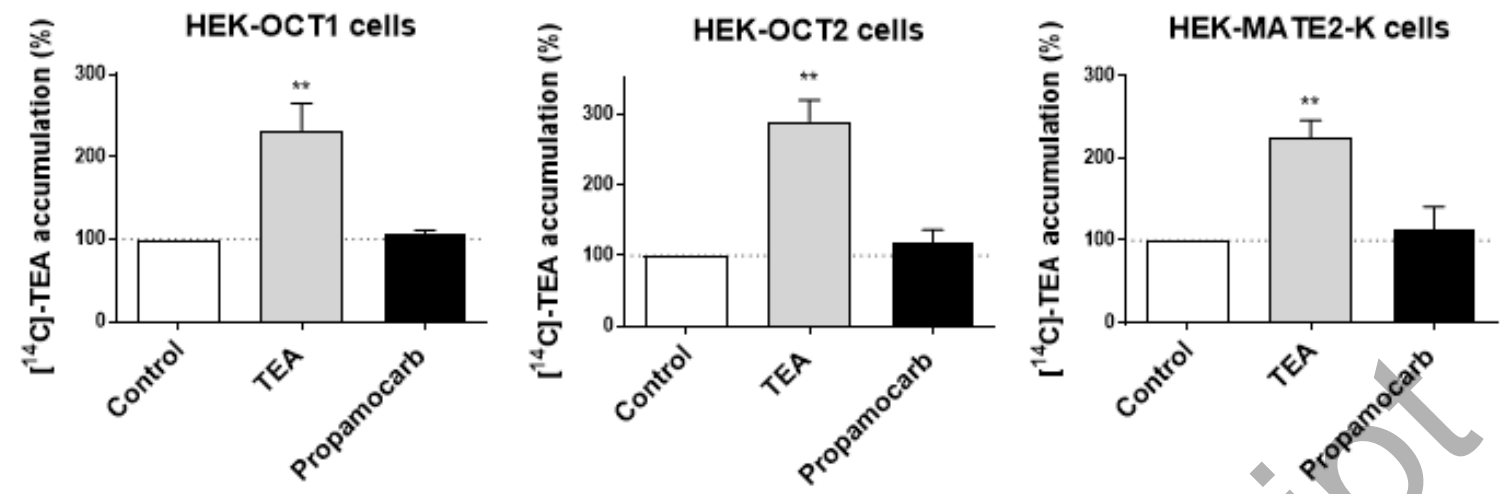

B
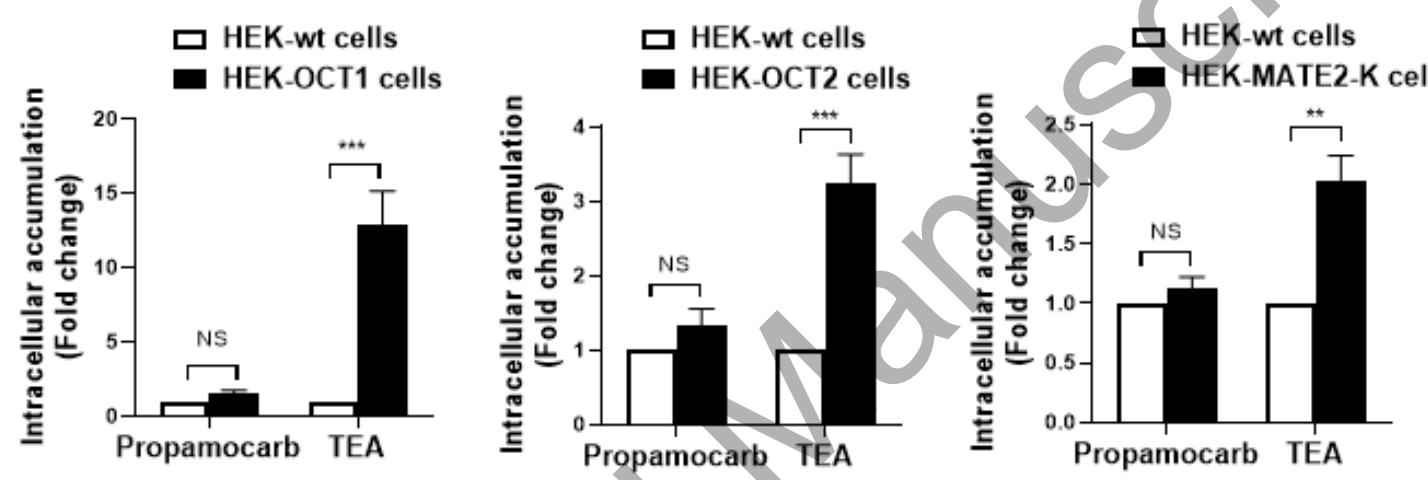

Figure 6. Trans-stimulating effect (A) and accumulation (B) of propamocarb in HEK-OCT1, HEK-OCT2 and HEK-MATE2-K cells. (A) Trans-stimulating effect of $100 \mu \mathrm{M}$ propamocarb or $2 \mathrm{mM}$ TEA towards OCT1-, OCT2- or MATE2-K-mediated uptake of $\left[{ }^{14} \mathrm{C}\right]$-TEA was 
determined in HEK-OCT1, HEK-OCT2 or HEK-MATE2-K cells. Data are expressed as \% of $\left[{ }^{14} \mathrm{C}\right]$-TEA accumulation in control cells, arbitrarily set at $100 \%$, and are the means \pm SEM of at least three independent assays. Dotted lines indicate $\left[{ }^{14} \mathrm{C}\right]$-TEA levels in control cells. ${ }^{* *}, \mathrm{p}$ $<0.01$ when compared to control. (B) Accumulation of $100 \mu \mathrm{M}$ propamocarb or $29 \mu \mathrm{M}\left[{ }^{14} \mathrm{C}\right]-$ TEA in HEK-OCT1, HEK-OCT2, HEK-MATE2-K and parental HEK-wt cells was determined by LC-MS/MS (propamocarb) or scintillation counting $\left(\left[{ }^{14} \mathrm{C}\right]-\mathrm{TEA}\right)$. Data are expressed as propamocarb or $\left[{ }^{14} \mathrm{C}\right]$-TEA accumulation fold-change comparatively to $\mathrm{HEK}$-wt cells and are the means \pm SEM of at least three independent assays. **, p $<0.01$; ***, p $<$ 0.001 ; NS, not statistically significant. 
Table 1: Prediction for in vivo transporter activity modulation by plasma concentrations of carbamate pesticides according to FDA criteria ${ }^{a}$

\begin{tabular}{|c|c|c|c|c|c|}
\hline $\begin{array}{c}\text { Carbamate } \\
\text { pesticide }\end{array}$ & $\begin{array}{c}\text { Approximated } \\
\mathbf{I}_{\text {max,u }}(\boldsymbol{\mu M})^{\mathbf{b}}\end{array}$ & Transporter & $\begin{array}{c}\mathbf{I C}_{\mathbf{5 0}} / \mathbf{E C}_{\mathbf{5 0}} \\
(\boldsymbol{\mu M})\end{array}$ & $\begin{array}{c}\text { Ratio } \\
\mathbf{I}_{\mathbf{m a x}, \mathbf{u}} / \mathbf{I C}_{\mathbf{5 0}} \mathbf{o r ~ E C}_{\mathbf{5 0}}\end{array}$ & $\begin{array}{c}\text { Potential in vivo } \\
\text { interaction with } \\
\text { transporter }\end{array}$ \\
\hline \multirow{2}{*}{ Chlorpropham } & \multirow{2}{*}{$0.0038^{\mathrm{c}}$} & $\mathrm{BCRP}$ & $53.2\left(\mathrm{IC}_{50}\right)$ & $<0.001$ & No inhibition \\
\cline { 3 - 6 } & \multirow{3}{*}{ Propamocarb } & OAT3 & $5.0\left(\mathrm{IC}_{50}\right)$ & $<0.001$ & No inhibition \\
\cline { 3 - 6 } & \multirow{2}{*}{$0.0038^{\mathrm{c}}$} & OCT1 & $48.1\left(\mathrm{IC}_{50}\right)$ & $<0.001$ & No inhibition \\
\cline { 3 - 6 } & & OCT2 & $38.1\left(\mathrm{IC}_{50}\right)$ & $<0.001$ & No inhibition \\
\cline { 2 - 6 } & MATE2-K & $4.6\left(\mathrm{EC}_{50}\right)$ & $<0.001$ & No stimulation \\
\hline
\end{tabular}

${ }^{\mathrm{a}}$ In vivo inhibition of drug transporter activity can be predicted if the ratio $\mathrm{I}_{\text {max, }} / \mathrm{IC}_{50} \geq 0.1$ (and by analogy in vivo stimulation of drug transporter activity may be predicted if the ratio $\mathrm{I}_{\max , \mathrm{u}} / \mathrm{EC}_{50} \geq 0.1$ ).

${ }^{\mathrm{b}}$ Defined as the maximum unbound plasma concentration.

${ }^{\mathrm{c}}$ From Li et al. (2018).

Table 2: Prediction for in vivo transporter activity inhibition by luminal gut concentrations of carbamate pesticides according to FDA criteria ${ }^{a}$

\begin{tabular}{|c|c|c|c|c|c|c|c|}
\hline $\begin{array}{c}\text { Carbamate } \\
\text { pesticide }\end{array}$ & $\begin{array}{c}\text { Admissible daily } \\
\text { intake (ADI) } \\
(\mathbf{m g} / \mathbf{k g} \text { body weight) }\end{array}$ & $\begin{array}{c}\text { Oral } \\
\mathbf{d o s e}^{\mathbf{c}} \\
(\boldsymbol{\mu m o l e})\end{array}$ & $\begin{array}{c}\mathbf{I}_{\text {gut }}^{\mathbf{d}} \\
(\boldsymbol{\mu M})\end{array}$ & Transporter & $\begin{array}{c}\mathbf{I C}_{\mathbf{5 0}} \\
(\boldsymbol{\mu M})\end{array}$ & $\begin{array}{c}\text { Ratio } \\
\mathbf{I}_{\mathbf{g u t}} / \mathbf{I C}_{\mathbf{5 0}}\end{array}$ & $\begin{array}{c}\text { Potential in } \\
\text { vivo inhibition } \\
\text { of } \text { transporter }\end{array}$ \\
\hline Chlorpropham & 0.05 & 8.2 & 32.8 & BCRP & 53.2 & 0.6 & No inhibition \\
\hline Propamocarb & 0.29 & 53.9 & 215.6 & OCT1 & 48.1 & 4.5 & No inhibition \\
\hline
\end{tabular}

${ }^{\mathrm{a}}$ In vivo inhibition of intestinal P-gp activity (and by analogy intestinal OCT1 activity) can be predicted if the ratio $\mathrm{I}_{\mathrm{gut}} / \mathrm{IC}_{50} \geq 10$.

${ }^{\mathrm{b}}$ According to the European Union-Pesticides database.

${ }^{\mathrm{c}}$ Defined for one meal and a $70 \mathrm{~kg}$ body weight.

${ }^{\mathrm{d}}$ Luminal gut concentration, calculated as the ratio oral dose $/ 250 \mathrm{~mL}$. 